\title{
Immunological Separation of Bioactive Natural Compounds from Crude Drug Extract and Its Application for Cell-Based Studies
}

\author{
Takuhiro Uto $^{1, *}$, Tomoe Ohta ${ }^{1}{ }^{1}$, Shunsuke Fujii ${ }^{2}$ and Yukihiro Shoyama ${ }^{1}$ \\ 1 Graduate School of Pharmaceutical Sciences, Nagasaki International University, 2825-7 Huis Ten Bosch-Cho, \\ Sasebo 859-3298, Japan; ohta@niu.ac.jp (T.O.); shoyama@niu.ac.jp (Y.S.) \\ 2 Faculty of Health Management, Nagasaki International University, 2825-7 Huis Ten Bosch-Cho, \\ Sasebo 859-3298, Japan; fujii@niu.ac.jp \\ * Correspondence: uto@niu.ac.jp; Tel.: +81-956-20-5653
}

Citation: Uto, T.; Ohta, T.; Fujii, S.; Shoyama, Y. Immunological Separation of Bioactive Natural Compounds from Crude Drug Extract and Its Application for Cell-Based Studies. Antibodies 2021, 10, 48. https://doi.org/10.3390/ antib10040048

Academic Editor: Itai Benhar

Received: 10 August 2021

Accepted: 30 November 2021

Published: 6 December 2021

Publisher's Note: MDPI stays neutral with regard to jurisdictional claims in published maps and institutional affiliations.

Copyright: (c) 2021 by the authors. Licensee MDPI, Basel, Switzerland. This article is an open access article distributed under the terms and conditions of the Creative Commons Attribution (CC BY) license (https:// creativecommons.org/licenses/by/ $4.0 /)$.

\begin{abstract}
In this study, we present a review on a useful approach, namely, immunoaffinity column coupled with monoclonal antibodies (MAbs), to separate natural compounds and its application for cell-based studies. The immunoaffinity column aids in separating the specific target compound from the crude extract. The column capacity was stable even after more than 10 purification cycles of use under the same conditions. After applying the crude extract to the column, the column was washed with washing buffer and eluted with elution buffer. The elution fraction contained the target compound bound to MAb, whereas the washing fraction was the crude extract, which contained all compounds except a group of target compounds; therefore, the washing fraction was referred to as a knockout $(\mathrm{KO})$ crude extract. Cell-based studies using the $\mathrm{KO}$ extract revealed the actual effects of the natural compounds in the crude extract. One-step separation of natural compounds using the immunoaffinity column coupled with MAbs may help in determining the potential functions of natural compounds in crude extracts.
\end{abstract}

Keywords: monoclonal antibody; immunoaffinity column; natural compound; one-step separation method; crude extract; knockout extract; ginseng; ginsenoside; licorice; glycyrrhizin

\section{Introduction}

Since ancient times, herbal medicines have been widely used in many Asian countries. Despite the great advances observed in modern medicine in recent decades, herbal medicines continue to make an important contribution to healthcare worldwide. The World Health Organization (WHO) has stated that herbal medicines are still the primary healthcare system for about $80 \%$ of the world's population, especially in developing countries [1]. Based on the importance of herbal medicines, analytical methods for bioactive natural compounds have been developed. Technical advances in instrumental analysis have allowed the detection of a wide variety of natural compounds using highly sensitive and selective methods. In addition, molecular approaches have revealed the mechanism of action of natural compounds through both in vivo and in vitro studies.

Monoclonal antibodies (MAbs) targeting high-molecular-weight molecules, such as proteins and peptides, have been widely used since 1975 [2]. A few decades ago, there were few MAbs targeting small-molecular-weight compounds, including natural compounds and synthetic drugs. However, the number of studies on MAbs against natural compounds has increased since the 1990s. Recently, a variety of MAbs against natural compounds have been developed, and some of them are commercially available. Our previous studies have produced more than 40 kinds of MAbs targeting natural compounds and have reported multiple applications based on these MAbs. Table 1 lists representative examples of MAbs and their applications in our studies and those of others. 
Table 1. Example of applications using MAbs against natural compounds.

\begin{tabular}{|c|c|c|c|}
\hline Target Compound & Plant Resource & Applications & References \\
\hline \multicolumn{4}{|l|}{ Monoterpene } \\
\hline \multirow{2}{*}{ Paeoniflorin, Albiflorin } & \multirow{2}{*}{ Paeonia lactiflora } & ELISA & [3] \\
\hline & & Immunostaining of plant section & [4] \\
\hline \multicolumn{4}{|l|}{ Sesquiterpenes } \\
\hline \multicolumn{4}{|l|}{$\begin{array}{l}\text { Antemisinim, } \\
\text { Artesunate }\end{array}$} \\
\hline \multicolumn{4}{|l|}{ Diterpene } \\
\hline \multirow{2}{*}{ Paclitaxel } & Taxus sp. & ELISA & {$[6,7]$} \\
\hline & & Time-resolved fluoroimmunoassay & [8] \\
\hline \multirow[t]{2}{*}{ Forskolin } & Coleus forskohlii & ELISA & [9] \\
\hline & & Immunoaffinity column & [10] \\
\hline \multicolumn{4}{|l|}{ Triterpene } \\
\hline \multirow[t]{5}{*}{ Glycyrrhizin } & Glycyrrhiza sp. & ELISA & {$[11,12]$} \\
\hline & & Eastern blot & [13] \\
\hline & & Double eastern blot & [14] \\
\hline & & Immunoaffinity column & [15] \\
\hline & & Selective breeding & [16] \\
\hline \multirow{3}{*}{$\begin{array}{l}\text { 3-Monoglucuronyl-glycyrrhetinic } \\
\text { acid }\end{array}$} & Glycyrrhiza sp. & ELISA & [17] \\
\hline & & $\begin{array}{l}\text { Immunodetection in plasma and } \\
\text { urine of patients }\end{array}$ & [17] \\
\hline & & Eastern blot & [18] \\
\hline \multirow[t]{6}{*}{ Ginsenoside Rb1 } & Panax sp. & ELISA & {$[19,20]$} \\
\hline & & Immunodetection in rat serum & {$[21,22]$} \\
\hline & & Eastern blot & [23] \\
\hline & & Double eastern blot & {$[24,25]$} \\
\hline & & Immunoaffinity column & [26] \\
\hline & & Cellular localization & [27] \\
\hline \multirow{3}{*}{ Ginsenoside Rg1 } & Panax sp. & ELISA & {$[20,28]$} \\
\hline & & Immunodetection in rat serum & [21] \\
\hline & & Double eastern blot & {$[24,25]$} \\
\hline \multirow{3}{*}{ Ginsenoside Re } & Panax sp. & ELISA & {$[20,29]$} \\
\hline & & Eastern blotting & [30] \\
\hline & & $\mathrm{KO}$ extract & [31] \\
\hline Notoginsenoside R1 & Panax notoginseng & ELISA & [32] \\
\hline \multirow[t]{2}{*}{ Saikosaponin a } & Bupleurum falcatum & ELISA & {$[33,34]$} \\
\hline & & Time-resolved fluoroimmunoassay & [35] \\
\hline \multicolumn{4}{|l|}{ Tetraterpene } \\
\hline Crocin & Crocus sativus & ELISA & [36] \\
\hline \multicolumn{4}{|l|}{ Chroman } \\
\hline Tetrahydrocannabinolic acid & Cannavis sativa & ELISA & [37] \\
\hline \multicolumn{4}{|l|}{ Quinone } \\
\hline Sennoside A, & Rheum sp., & ELISA & [38] \\
\hline Sennoside B & Senna sp. & Eastern blotting & [39] \\
\hline \multirow{2}{*}{ Plumbagin } & Plumbago zeylanica & ELISA & {$[40,41]$} \\
\hline & & Molecular breeding & [42] \\
\hline Alkaloid & & & \\
\hline Berberine & $\begin{array}{l}\text { Phellodendron amurense } \\
\text { Coptis japonica }\end{array}$ & ELISA & {$[43,44]$} \\
\hline Solamargine & Solanum khasianum & ELISA & [45] \\
\hline & & Eastern blotting & [46] \\
\hline & & Immunoaffinity column & [47] \\
\hline & & Molecular breeding & [48] \\
\hline Aristolochic acid-I, -II & Aristolochia species & ELISA & [49] \\
\hline & & Eastern blot & [50] \\
\hline & & Cellular localization & [51] \\
\hline & & Determination of target molecular & [52] \\
\hline Harringtonine & genus Cephalotaxus & ELISA & [53] \\
\hline & & $\begin{array}{l}\text { Immunochromatographic strip } \\
\text { assay }\end{array}$ & [54] \\
\hline & & Cellular uptake & [55] \\
\hline
\end{tabular}


Table 1. Cont.

\begin{tabular}{lllr}
\hline \multicolumn{1}{c}{ Target Compound } & \multicolumn{1}{c}{ Plant Resource } & \multicolumn{1}{c}{ Applications } & References \\
\hline $\begin{array}{l}\text { Flavonoid } \\
\text { Liquiritin }\end{array}$ & Glycyrrhiza sp. & ELISA & {$[12,56]$} \\
& & Double eastern blot & {$[14]$} \\
& & Quality control & {$[56]$} \\
Baicalin, Baicalein & Scutellaria baicalensis & ELISA & {$[57]$} \\
Kwakhurin & Pueraria candollei & ELISA & {$[58,59]$} \\
vararin & var. mirifica & ELISA & {$[60]$} \\
Paidzin & Glycine max & Immunoaffinity column & {$[60]$} \\
& Citrus sp. & ELISA & {$[61]$} \\
Naringin & & ELISA & {$[61]$} \\
& & Immunoaffinity column & {$[62]$} \\
\hline
\end{tabular}

Enzyme-linked immunosorbent assay (ELISA) with MAbs targeting natural compounds is useful for the quality control of natural products because of their high sensitivity. Moreover, ELISA listed in Table 1 is rapid and does not require pretreatment and organic solvent when compared to other analytical methods, such as high-performance liquid chromatography (HPLC) and HPLC-mass spectrometry. We also developed "Eastern blotting", which is an on-membrane quantitative analytical system, using MAbs against natural compounds $[13,14,18,23-25,30,39,46,50]$. Eastern blotting is a unique immunostaining method for detecting target natural compounds on a membrane, which has fixed natural compounds transferred from TLC. Furthermore, we applied MAb for the molecular breeding of medicinal plants. In the first step, a recombinant single-chain fragment variable $(\mathrm{scFv})$ antibody was constructed from hybridoma cells expressing MAb against natural compounds. The scFv antibody gene was introduced into the host plant. The scFv antibody was found to express in transgenic plants and activate the biosynthesis of secondary metabolites. This plant breeding methodology can be used as a potential tool to enhance bioactive compounds $[42,48]$.

Affinity chromatography is one of the most diverse and powerful chromatographic methods for selective purification of a molecule or group of molecules from complex mixtures. For example, cell membrane chromatography is an efficient method for the detection of bioactive components acting on a specific receptor from a complex biological system [63]. One of the applications of MAbs against natural compounds is immunoaffinity purification and separation. Immunoaffinity purification using MAb is a useful methodology for purifying larger molecules, such as proteins and peptides. However, there are only a few studies on immunoaffinity purification targeting small-molecular-weight compounds, such as natural compounds. An immunoaffinity column with MAb targeting natural compounds has made it possible to carry out single-step purification and separation of target compounds from crude drug extract. We have developed immunoaffinity columns against forskolin [10], glycyrrhizin [15], ginsenoside Rb1 [26], and solamargine [47]. Additionally, other groups have demonstrated immunoaffinity columns against puerarin [60], daizin [61], and naringin [62]. In this review, we introduce the preparation of an immunoaffinity column with MAbs targeting natural compounds and carry out one-step separation of natural compounds from crude extract using the column. Furthermore, we describe the application of this approach for cell-based studies that use fractions, which are prepared by eliminating one target compound from the crude extract using the immunoaffinity column.

\section{Preparation of the Immunoaffinity Column with MAbs against Bioactive Natural Compounds and One-Step Separation of Natural Compounds from Crude Extract Using the Column}

IgG contains approximately 3\% carbohydrate in the Fc region (heavy chain) of the antibody. Periodate oxidation of vicinal hydroxyl groups of these carbohydrates forms aldehyde group, which can be coupled to Affi-Gel Hz hydrazide gel (Bio-Rad) to form stable hydrazones. The purified MAb was treated with $\mathrm{NaIO}_{4}$, leading to the formation 
of a dialdehyde group on the sugar moiety, and the oxidized MAb was coupled with the gel to form a hydrozone-type immunoaffinity gel (Figure 1) $[15,26,47]$. In the following sections, we introduce immunoaffinity columns with MAbs against ginsenoside Rb1 and glycyrrhizin, and their clinical application.

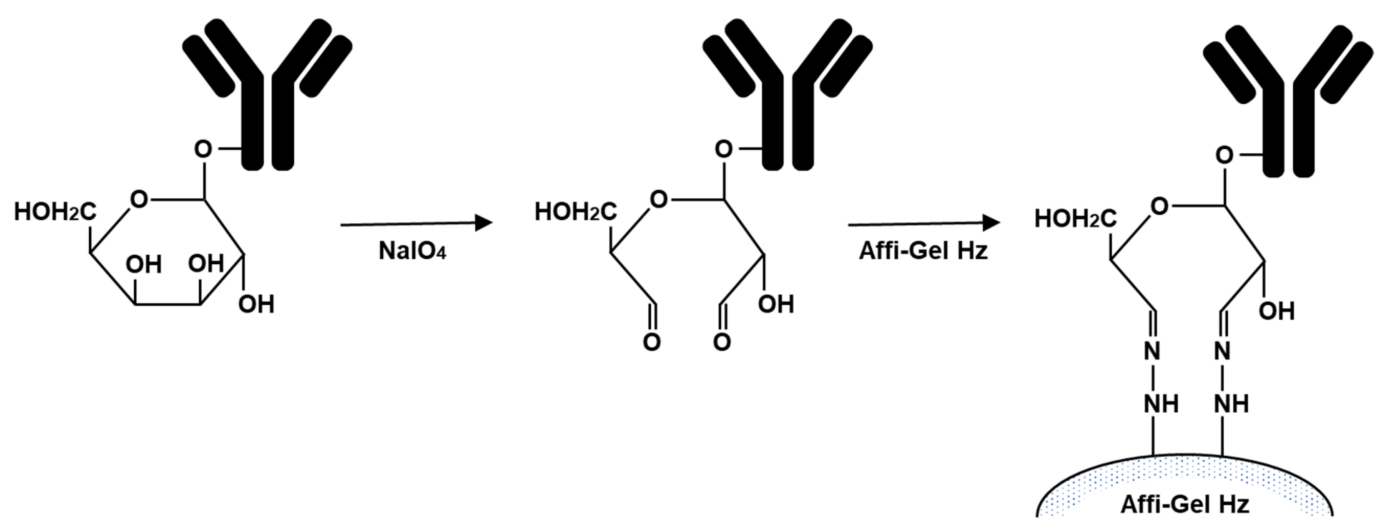

Figure 1. Scheme of the preparation of an immunoaffinity column with MAbs against natural compounds.

Ginseng, the root of Panax ginseng, has been used for thousands of years in China, Korea, and Japan as an important crude drug in traditional Chinese medicine and Japanese Kampo medicine. Ginsenosides are the main pharmacologically active compounds in ginseng. Basic and clinical studies have demonstrated that ginsenosides exert various pharmacological activities, such as antioxidative and anticancer effects, which improves immunity, energy and sexuality, cardiovascular diseases, diabetes, and neurological diseases [64]. Ginsenosides are a special group of triterpenoid saponins that can be classified into two groups: protopanaxadiol (PPD) and protopanaxatriol (PPT), which possess a dammarane skeleton in their molecules. To date, more than 150 ginsenosides have been isolated from the roots, leaves, stems, fruits, and flower heads of ginseng $[64,65]$. Ginseng contains many ginsenosides with similar structures; thus, the separation of specific ginsenosides from ginseng crude extract is difficult. Preparative HPLC can separate and purify individual ginsenosides from crude extracts. However, the disadvantages of preparative HPLC are the cost of the stationary columns, volume of solvents, and run times. In addition, it is difficult to separate specific compounds from the crude extract and finally prepare the specific compound-eliminated crude extract.

Ginsenoside Rb1 (G-Rb1, Figure 2a) is a PPD-type ginsenoside, and we established anti-G-Rb1 MAb and performed ELISA $[19,20]$. The cross-reactivities of MAb with other PPD-type ginsenosides Rc and Rd were $0.024 \%$ and $0.020 \%$, respectively, compared to that with G-Rb1 $[19,20]$. Thus, MAb may predominantly react with G-Rb1 but not with its structurally related ginsenosides. We prepared an immunoaffinity column by coupling $\mathrm{MAb}$ with an Affi-Gel Hz gel [26]. The purified $10 \mathrm{mg}$ of IgG diluted in Affi-Gel Hz coupling buffer (Bio-Rad, commercially available) was dialyzed against the coupling buffer. One microliter of the IgG solution was reacted with $100 \mathrm{~mL}$ of $\mathrm{NaIO}_{4}$ solution $(25 \mathrm{mg} / 1.2 \mathrm{~mL}$ $\mathrm{H}_{2} \mathrm{O}$ ), and stirred at room temperature for $1 \mathrm{~h}$ in a container covered with foil. To inactivate $\mathrm{NaIO}_{4}$, glycerol was immediately added to the mixture at a final concentration of $20 \mathrm{mM}$ and stirred for $10 \mathrm{~min}$. The mixture containing the oxidized MAb was dialyzed against the coupling buffer again. After the Affi-Gel Hz hydrazide gel was washed with the coupling buffer, the oxidized and desalted anti-G-Rb1-MAb was then coupled with the gel for $24 \mathrm{~h}$ with gentle stirring at room temperature for $24 \mathrm{~h}$. After completing the coupling reaction, the gel was slurry-poured into a mini-column. The column was washed with $20 \mathrm{mM}$ of phosphate buffer (PB) containing $0.5 \mathrm{M} \mathrm{NaCl}(\mathrm{pH} 7.0)$. The eluates were collected and used for the determination of coupling efficiency by direct ELISA [19]. Finally, the column was washed with phosphate buffer saline (PBS) until the ELISA value was equal to the 
background, then the column in PBS containing $0.02 \%$ sodium azide was stored at $4{ }^{\circ} \mathrm{C}$ until ready for use.

(a)

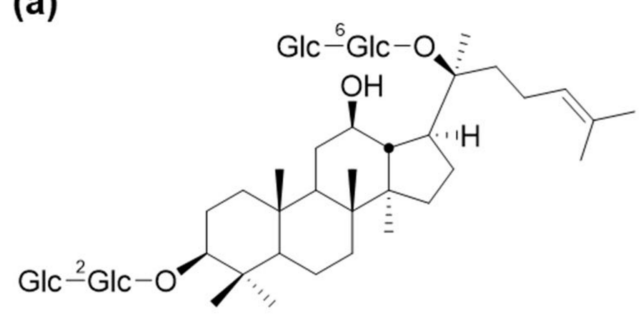

(c)

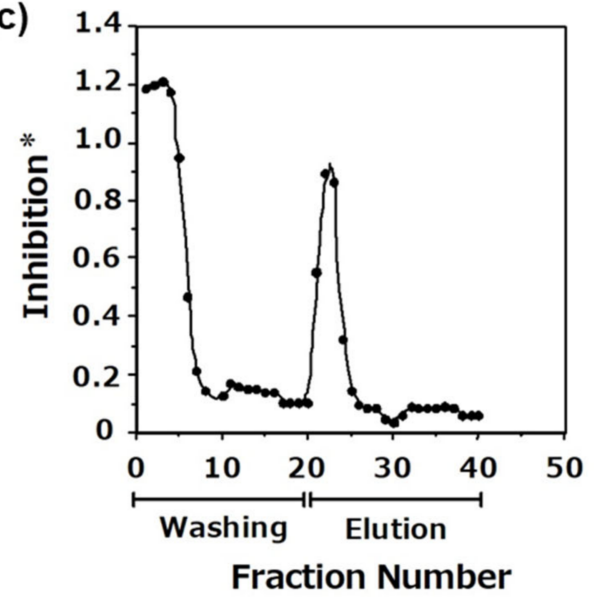

(b) Washing Buffer Elution Buffer

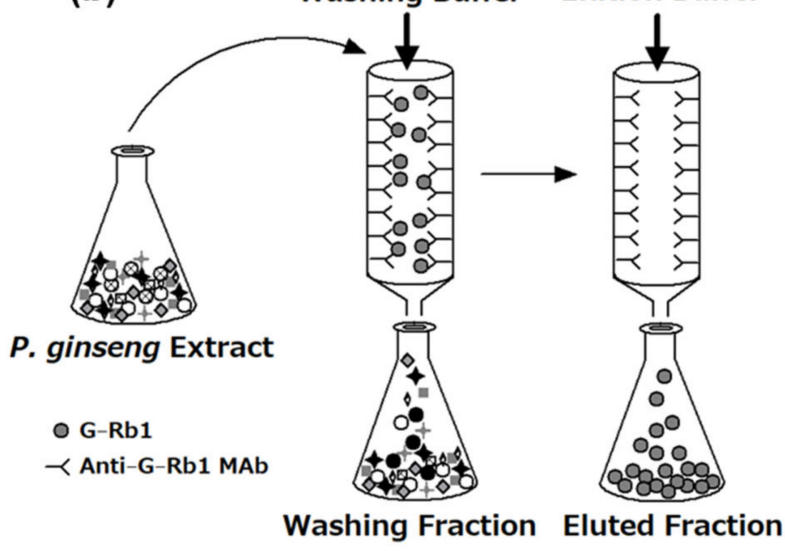

(d)

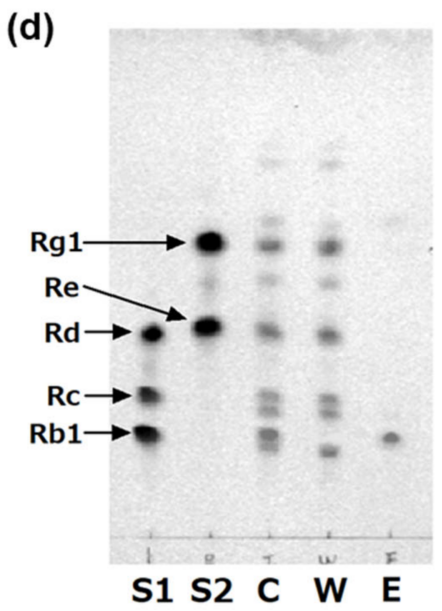

Figure 2. (a) Chemical structure of G-Rb1. (b) Scheme showing the fractionation using the anti-G-Rb1 MAb-coupled immunoaffinity column. (c) Elution profile of the P. ginseng crude extract separated using the immunoaffinity column. ELISA using anti-G-Rb1 MAb determined the concentrations of G-Rb1 in each fraction (1-40). * Inhibition = $(\mathrm{A} 0-\mathrm{A}) / \mathrm{A} 0$, where $\mathrm{A} 0$ is the absorbance in the absence of the test compounds and $\mathrm{A}$ is the absorbance in the presence of the test compounds. (d) TLC profile of the fractions obtained from the immunoaffinity column. S1: G-Rd, G-Rc, and G-Rb1, S2: G-Rg1 and G-Re, C: P. ginseng crude extract, W: washing fraction, E: eluted fraction.

The crude extract of P. ginseng (3.8 mg) was dissolved in loading buffer (PBS), applied to the immunoaffinity column, and completely washed with the washing buffer (PBS), and then eluted with $100 \mathrm{mM}$ HOAc buffer containing $0.5 \mathrm{M} \mathrm{KSCN}$ and $20 \% \mathrm{MeOH}(\mathrm{pH} 4.0)$ (Figure $2 \mathrm{~b}$ ). Figure $2 \mathrm{c}$ shows the elution profile of the anti-G-Rb1 immunoaffinity column with anti-G-Rb1 MAb using ELISA. The concentrations of G-Rb1 in each fraction could be easily monitored by this system, so we can know when the column was completely washed. The overcharged G-Rb1 was detected in fractions 1-8. G-Rc, Rd, Re, and Rg1 were also present in these fractions. After washing the column, G-Rb1 was eluted with the elution buffer and detected around fractions 20-24. However, few malonyl G-Rb1 moieties were contaminated in fractions 20-24 because anti-G-Rb1 MAb also reacted with malonyl G-Rb1. Thus, the eluted fraction was treated with a mild alkaline solution at room temperature for $1 \mathrm{~h}$ to obtain pure G-Rb1. The washing fractions containing overcharged G-Rb1 were repeatedly applied to the same columns, and G-Rb1 was finally separated from the crude extract. These data demonstrated that G-Rb1, as target compounds, are stable during the separation process. This anti-G-Rb1 immunoaffinity column had the capacity for approximately $20 \mu \mathrm{g}$ of G-Rb1/mL of gel [26]. 
After collection, the washing and eluted fractions were deionized and lyophilized. Figure $2 \mathrm{~d}$ shows the TLC profiles of each fraction. A standard of ginsenosides was spotted on S1 (G-Rd, G-Rc, and G-Rb1) and S2 (G-Rg1 and G-Re). All spots of ginsenosides were detected in the crude extract (C). By contrast, the washing fraction (W) contained all ginsenosides except G-Rb1, suggesting that the column selectively eliminated G-Rb1 from the crude extract. Furthermore, G-Rb1 was detected in the eluted fractions (E). Due to the washing fraction only containing G-Rb1 from the crude extract, this fraction was referred to as the G-Rb1-knockout $(\mathrm{KO})$ ginseng extract [26]. These data indicate the specificity and high efficiency of the immunoaffinity column for eliminating the target compound from the crude extract.

Licorice, the root of Glycyrrhiza sp., has long been used worldwide as an herbal medicine. Licorice is registered in the United States Pharmacopoeia 43rd Edition [66], and it is registered as Glycyrrhiza in the Japanese Pharmacopeia 17th Edition (JP XVII) [67]. Licorice is used in more than $70 \%$ of Japanese Kampo medicines for the treatment of sore throats. Licorice is also used as a natural sweetener for food and confectionery. The accumulated data on biological activity suggest that licorice exerts antibacterial, antiviral, anti-inflammatory, anticancer, antioxidant, liver protection, neuroprotection, skin whitening, hypoglycemic, memory-enhancing, and other biological activities [68-71].

Numerous phytochemical studies have shown that licorice contains numerous bioactive components, including more than 20 triterpenoids and nearly 300 flavonoids [72]. GC (Figure 3), also known as glycyrrhizic acid, is a major bioactive component of licorice and belongs to the triterpene saponin. GC possesses many pharmacological properties, such as antibacterial, antitumor, antiviral, anti-inflammatory, and immunostimulatory activities [73]. In licorice crude extract, GC is present in the highest amount $(>2 \%)$, and its content in wild, high-quality licorice can be as high as 7\% [74]. We previously established anti-GC MAb and reported its application using ELISA and Eastern blotting $[13,14]$. The cross-reactivity of anti-GC MAb with 3-monoglucuronyl-glycyrrhetinic acid (3MGA) and glycyrrhetinic acid (GA) was $0.585 \%$ and $1.865 \%$, respectively. The cross-reactivity of anti-GC MAb with other related compounds including deoxycholic acid, ursolic acid, and oleanolic acid was $<0.005 \%$. Thus, ELISA and Eastern blotting, which we established, specifically reacted with GC [13]. To identify high-GC-producing plants, we screened 1025 samples of G. uralensis root using a combination of ELISA and Eastern blot and found that the highest concentration of GC was $5.36 \mathrm{dw} \%$ among the screened samples [16].

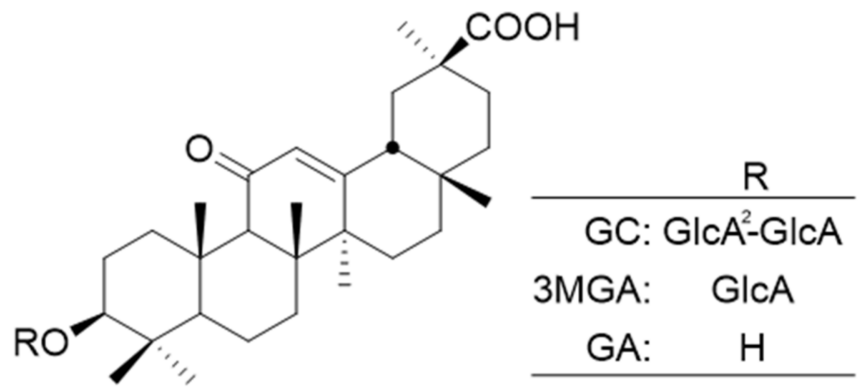

Figure 3. Chemical structures of GC, 3MGA, and GA.

Similar to anti-G-Rb1 MAb, anti-GC MAb was coupled with an Affi-Gel $\mathrm{Hz}$ gel to prepare an immunoaffinity column, which can extract GC from the licorice crude extract [15]. The purified $50 \mathrm{mg}$ anti-GC MAb was coupled with $25 \mathrm{~mL}$ of an Affi-Gel Hz gel. In the same way as the G-Rb1, anti-GC MAb oxidized with $\mathrm{NaIO}_{4}$ by mixing gently in the dark for $1 \mathrm{~h}$, then glycerol was added for the inactivation of $\mathrm{NaIO}_{4}$. After dialysis, the oxidized anti-GC-MAb was coupled to the Affi-Gel Hz hydrazide gel for $24 \mathrm{~h}$ with gentle stirring at ambient temperature. The gel was poured into a plastic mini-column and the column was washed with $20 \mathrm{mM} \mathrm{PB}$ containing $0.5 \mathrm{M} \mathrm{NaCl}$ (pH 7.0). The eluates were collected and saved for coupling efficiency determination. The coupling efficiency of 
the anti-GC-MAb to Affi-Gel Hz was determined to be $95.21 \%$ using a sandwich ELISA to measure uncoupled MAb.

This affinity column specifically and completely eliminated GC from the crude licorice extract. Twelve milligrams of crude extract containing $1275.0 \mu \mathrm{g}$ of GC was dissolved in loading buffer ( $5 \mathrm{mM}$ PB-5\% MeOH-50 mM NaCl, pH 7.0) and applied to the immunoaffinity column. The loading buffer was mechanically circulated through the column to enhance the binding efficiency of GC. After overnight circulation, the unbound fraction was collected. The column was then washed with washing buffer $(20 \mathrm{~mL}$ of $5 \mathrm{mM} \mathrm{PB}-50 \mathrm{mM} \mathrm{NaCl}$, $\mathrm{pH}$ 7.0) and eluted with elution buffer (20 mM PB-30\% MeOH-500 mM NaCl, pH 7.0). After deionization and lyophilization of the solvent in each fraction, the GC concentration was determined using ELISA. The GC concentrations in the unbound and bound fractions were $3.50 \mu \mathrm{g}(0.27 \%$ of the applied GC) and $1269.26 \mu \mathrm{g}(99.55 \%$ of the applied GC), respectively (Figure 4a). In other words, the anti-GC immunoaffinity column eliminated $99.55 \%$ of the loaded GC and the capacity of the anti-GC immunoaffinity column was approximately $33.5 \mu \mathrm{g}$ of $\mathrm{GC} / \mathrm{mL}$ of gel. The obtained unbound fraction was the licorice crude extract lacking only GC; therefore, this unbound fraction had the GC-KO licorice extract. TLC analysis of the GC-KO licorice extract indicated that GC was specifically removed from the GC-KO licorice extract (Figure $4 \mathrm{~b}$ ). In addition, eastern blotting using anti-GC MAb could not detect GC in the GC-KO licorice extract. HPLC fingerprint analysis demonstrated that although the GC-KO licorice extract contained three licorice flavonoids, namely, liquiritin, liquiritigenin, and isoliquiritigenin, in the same pattern as that in the licorice extract, only GC was undetectable in the GC-KO licorice extract (Figure 4c).

In order to determine the purity of target compounds, we analyzed the eluted fractions by ELISA analysis and Eastern blotting, suggesting that the eluted fractions contained only target compounds bound to MAbs. Although the preparation of the immunoaffinity columns consumes a large amount of MAbs, the column is reusable after cleaning. The column capacity was stable even after more than 10 purification cycles under the same conditions, similar to the one-step separation of forskolin present in the crude extract of Coleus forskohlii root [10]. According to the ELISA analysis of eluted fraction from the anti-GC immunoaffinity column, this column could be regenerated in excess of 20 times without an obvious loss of capacity (from about $33 \mu \mathrm{g} / \mathrm{mL}$ gel to about $29 \mu \mathrm{g} / \mathrm{mL}$ gel) [15]. Generally, the purification and separation of natural compounds have been performed by HPLC and chromatographic techniques, but these are tedious and time-consuming procedures. Compared with these conventional methods, the methodology using the immunoaffinity column is simple and specific. In addition, once the column is prepared, it is reusable several times without a loss in activity. Recently, molecular imprinted polymers (MIP) have attracted wide attention and attained significant applications in the identification and separation of various natural compounds [75]. MIP is useful tool to isolate natural compounds, but MIP applications in the analytical determination of natural compounds such as polyphenols metabolites have been limited and few used phenolic acid as a template [76]. In addition, the preparation of KO extracts using MIP has never been reported before. Thus, the immunoaffinity column with MAbs against natural compounds is only tool to prepare $\mathrm{KO}$ extracts. 
(a)

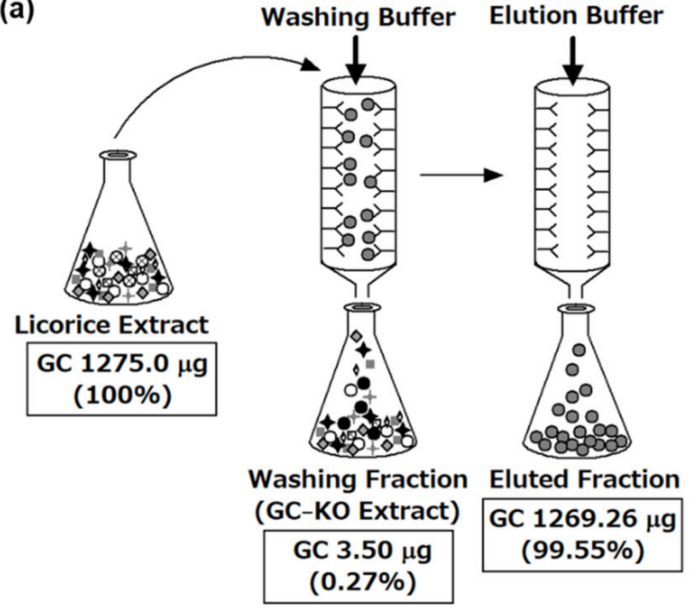

(b)

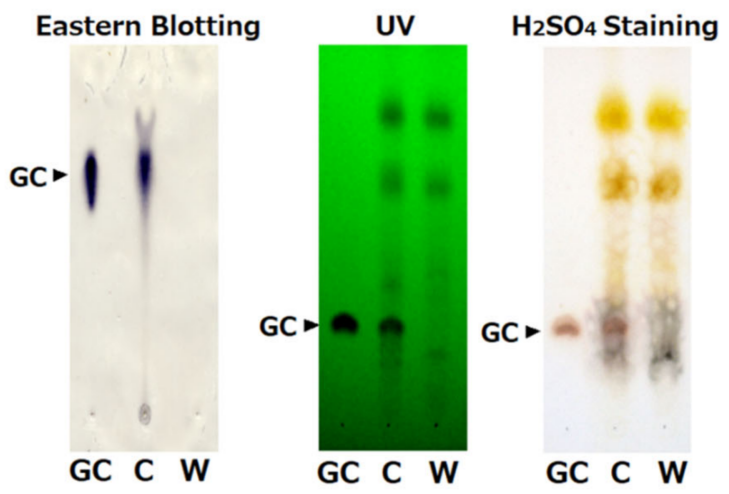

(c)

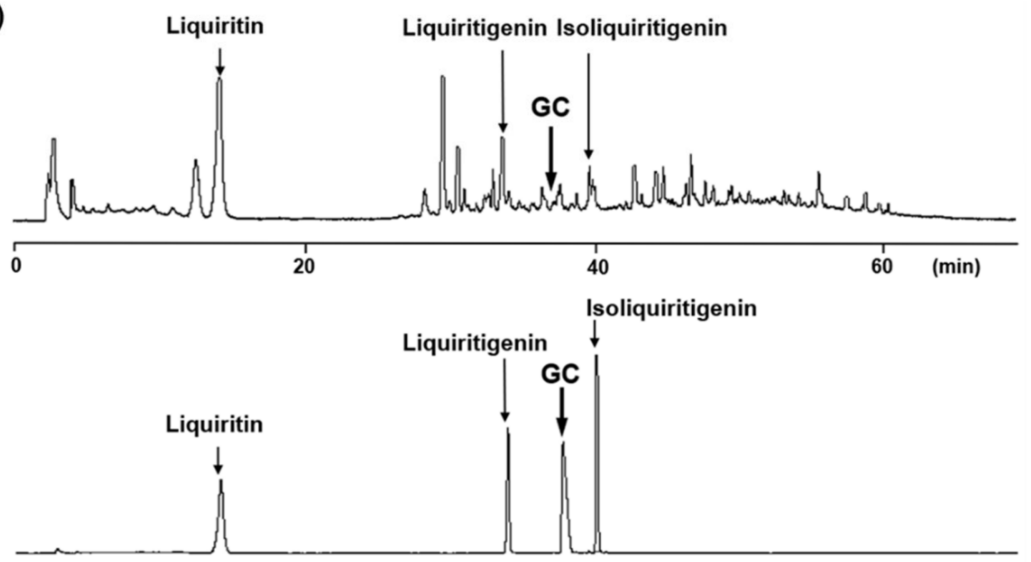

Figure 4. (a) Scheme of the preparation of GC-KO extract using the anti-GC MAb-coupled immunoaffinity column and the GC concentration in each fraction. (b) TLC profiles of the fractions obtained from the immunoaffinity column. C: licorice crude extract; W: washing fraction. (c) HPLC profile of the washing fraction (upper panel), GC, and three licorice flavonoids (lower).

\section{Cell-Based Studies Using the GC-KO Licorice Extract}

The $\mathrm{KO}$ extract is a useful tool for evaluating the interaction or synergistic actions between the target compound and other compounds present in the crude extract. In this section, we present two previous reports that have performed cell-based studies using the GC-KO licorice extract.

The first example of a study using the GC-KO licorice extract is to clarify the role of GC in the suppression of nitric oxide (NO) production [77]. The licorice extract suppressed NO production in lipopolysaccharide-treated murine RAW264 macrophages (inhibition ratio $(\mathrm{IR})=57.7 \%$ ). On the contrary, single treatment of GC could not significantly inhibit NO production. Therefore, it seems that the GC-KO licorice extract can inhibit NO production to a level similar to that of the licorice extract because single treatment of GC did not inhibit NO production. Interestingly, although GC alone did not block NO production, the inhibitory effect of the GC-KO extract (IR = 17.8\%) was weaker than that of the licorice extract $(\mathrm{IR}=57.7 \%)$. Moreover, co-treatment with the GC-KO extract and GC strikingly improved the inhibitory potency ( $\mathrm{IR}=33.5 \%$ ). A similar pattern was found for the protein expression levels of inducible NO synthase, which produces NO from L-arginine. These data indicate that GC alone cannot attenuate NO production, but GC suppresses NO production with the other constituents of licorice. Moreover, a similar phenomenon was observed when we compared the antiproliferative activity and apoptosis induction of licorice extract and GC-KO extract on antiproliferative activity and apoptosis induction in human leukemia HL-60 cells [78]. These data imply the synergistic interactions of GC and other constituents in the licorice extract. 
In the second study, GC-KO licorice extract was used to explore the effect of licorice extract on high glucose-induced tubular epithelial-to-mesenchymal transition (EMT) [79]. In renal tubular NRK-52E cells exposed to high-glucose, GC-KO extract provided equivalent efficacy compared with that of the licorice extract in suppressing EMT via Notch2 signaling pathway. By contrast, GC had little influence on EMT. Although GC is a major bioactive component, licorice extract contains various other bioactive components [69,72]. Thus, these data indicated that GC was not directly involved in the suppression of EMT, and both licorice and GC-KO extracts could prevent renal tubular EMT and fibrosis in diabetic nephropathy. Future studies are needed to elucidate the role of GC on EMT.

The two previous studies demonstrated that the KO extract is helpful for identifying the potential role of target compounds in crude extract in cell-based studies. Similar to the G-Rb1-KO extract and the GC-KO extract, several immunoaffinity columns and KO extracts were reported by our group and other groups (Table 1) [60-62]. The selectivity of the column is dependent on the MAbs conjugated with Affi-Gel Hz gel. The MAb against solasodine has wide cross-reactivity. The immunoaffinity column coupled with anti-solamargine MAb could separate total solasodine glycosides from the crude extract of Solanum khasianum seeds [46]. In other words, this column can concentrate the total solasodine glycosides from plant materials. Therefore, this methodology can be available for the detection of higher yielding solasodine glycosides plantlets in vitro of S. khasianum by the combination with ELISA because the regenerated plantlets contain a small amount of solasodine glycosides. Qu et al. prepared the immunoaffinity column by coupling the MAbs against daizin and naringin to CNBr-activated Sepharose 4B. The immunoaffinity column coupled with anti-daizin MAb can efficiently and specifically extract daidzin, glycitein, and genistin from numerous structurally similar soy isoflavones in leguminous plants [61]. On the other hand, the column coupled with anti-naringin MAb can capture approximately $250 \mu \mathrm{g}$ of naringin without cross reacting with its structurally similar compounds [62]. Taken together, these studies imply that various immunoaffinity column having different cross-reactivity against natural compounds can be established and applied for the preparation of $\mathrm{KO}$ extracts.

\section{Conclusions}

This review discusses the one-step purification of bioactive natural compounds from crude extracts using an immunoaffinity column coupled with MAbs against natural compounds. G-Rb1 and GC were selectively separated from $P$. ginseng and licorice crude extract by the column using MAbs against G-Rb1 and GC, respectively. The obtained washing fractions were eliminated only target compound from the crude extract; therefore, this fraction is referred to as $\mathrm{KO}$ extract. This immunoaffinity column selectively separated target compounds from the original extract without time-consuming and complicated procedures. Once the column is prepared, the column is stable and reusable for more than 10 cycles under the same conditions. This methodology may be applied to other kinds of natural compounds not yet been developed. The selectivity of the column is dependent on the MAbs, thus when the column is coupled with a broad cross-reactive MAb, it is possible to separate a group of target compounds, not only one kind of compound, from the extract. Indeed, we demonstrated that total ginseng saponins were separated by the column using anti-G-Re MAb, which has a broad cross-reactivity with ginsenosides [29]. The immunoaffinity columns can be applicable for a high-sensitivity detection of the target compounds by combination with ELISA. In our previous study, the combination of column and ELISA using anti-G-Rb1 detected G-Rb1 in Kalopanax pictus Nakai, which was not previously reported to contain ginsenosides [23]. We also applied KO extract for investigating the functions of natural compounds in cell-based studies. The KO extracts may be useful tool to clarify the actual effects of the bioactive compound and elucidate interactions between the target compound and the other compounds in the crude extracts, including Japanese Kampo medicines and traditional Chinese medicines. 
Author Contributions: Conceptualization, T.U. and Y.S.; writing-original draft preparation, T.U., T.O. and S.F.; writing - review and editing, T.U. All authors have read and agreed to the published version of the manuscript.

Funding: This study was partly supported by JSPS KAKENHI Grant Number 19K07145 and 25871011.

Data Availability Statement: Data in this study will be provided upon reasonable request to the corresponding author.

Acknowledgments: The authors sincerely thank the Association for Health Economics Research and Social Insurance and Welfare for financial assistance.

Conflicts of Interest: The authors declare no conflict of interest.

\section{References}

1. WHO. WHO Traditional Medicine Strategy 2014-2023; World Health Organization: Geneva, Switzerland, 2013.

2. Köhler, G.; Milstein, C. Continuous cultures of fused cells secreting antibody of predefined specificity. Nature 1975, 256, 495-497. [CrossRef] [PubMed]

3. Lu, Z.; Morinaga, O.; Tanaka, H.; Shoyama, Y. A quantitative ELISA using monoclonal antibody to survey paeoniflorin and albiflorin in crude drugs and traditional Chinese herbal medicines. Biol. Pharm. Bull. 2003, 26, 862-866. [CrossRef] [PubMed]

4. Morinaga, O.; Lu, Z.; Lin, L.; Uto, T.; Sangmalee, S.; Putalun, W.; Tanaka, H.; Shoyama, Y. Detection of paeoniflorin and albiflorin by immunostaining technique using anti-paeoniflorin monoclonal antibody. Phytochem. Anal. 2013, 24, 124-128. [CrossRef] [PubMed]

5. Tanaka, H.; Putalun, W.; De-Eknamkul, W.; Matangkasombut, O.; Shoyama, Y. Preparation of a novel monoclonal antibody against the antimalarial drugs, artemisinin and artesunate. Planta Med. 2007, 73, 1127-1132. [CrossRef]

6. Chao, Z.; Tan, M.; Paudel, M.K.; Sakamoto, S.; Ma, L.; Sasaki-Tabata, K.; Tanaka, H.; Shoyama, Y.; Xuan, L.; Morimoto, S. Development of an indirect competitive enzyme-linked immunosorbent assay (icELISA) using highly specific monoclonal antibody against paclitaxel. J. Nat. Med. 2013, 67, 512-518. [CrossRef] [PubMed]

7. Yusakul, G.; Sakamoto, S.; Tanaka, H.; Morimoto, S. Improvement of heavy and light chain assembly by modification of heavy chain constant region 1 (CH1): Application for the construction of an anti-paclitaxel fragment antigen-binding (Fab) antibody. J. Biotechnol. 2018, 288, 41-47. [CrossRef]

8. Cui, Q.; Tanaka, H.; Shoyama, Y.; Ye, H.T.; Li, F.; Tian, E.W.; Wu, Y.S.; Chao, Z. Development of a competitive time-resolved fluoroimmunoassay for paclitaxel. Phytochem. Anal. 2018, 29, 284-289. [CrossRef] [PubMed]

9. Sakata, R.; Shoyama, Y.; Murakami, H. Production of monoclonal antibodies and enzyme immunoassay for typical adenylate cyclase activator, Forskolin. Cytotechnology 1994, 16, 101-108. [CrossRef] [PubMed]

10. Yanagihara, H.; Sakata, R.; Shoyama, Y.; Murakami, H. Rapid analysis of small samples containing forskolin using monoclonal antibodies. Planta Med. 1996, 62, 169-172. [CrossRef]

11. Tanaka, H.; Shoyama, Y. Formation of a monoclonal antibody against glycyrrhizin and development of an ELISA. Biol. Pharm. Bull. 1998, 21, 1391-1393. [CrossRef] [PubMed]

12. Fujii, S.; Morinaga, O.; Uto, T.; Nomura, S.; Shoyama, Y. Simultaneous determination of glycyrrhizin and liquiritin in licorice roots and Kampo medicines by combination enzyme-linked immunosorbent assay using anti-glycyrrhizin and anti-liquiritin monoclonal antibodies. J. Immunoass. Immunochem. 2017, 38, 285-298. [CrossRef] [PubMed]

13. Shan, S.; Tanaka, H.; Shoyama, Y. Enzyme-linked immunosorbent assay for glycyrrhizin using anti-glycyrrhizin monoclonal antibody and an eastern blotting technique for glucuronides of glycyrrhetic acid. Anal. Chem. 2001, 73, 5784-5790. [CrossRef]

14. Fujii, S.; Morinaga, O.; Uto, T.; Nomura, S.; Shoyama, Y. Development of double eastern blotting for major licorice components, glycyrrhizin and liquiritin for chemical quality control of licorice using anti-glycyrrhizin and anti-liquiritin monoclonal antibodies. J. Agric. Food Chem. 2016, 64, 1087-1093. [CrossRef]

15. Xu, J.; Tanaka, H.; Shoyama, Y. One-step immunochromatographic separation and ELISA quantification of glycyrrhizin from traditional Chinese medicines. J. Chromatogr. B Analyt. Technol. Biomed. Life Sci. 2007, 850, 53-58. [CrossRef] [PubMed]

16. Fujii, S.; Tuvshintogtokh, I.; Mandakh, B.; Munkhjargal, B.; Uto, T.; Morinaga, O.; Shoyama, Y. Screening of Glycyrrhiza uralensis Fisch. ex DC. containing high concentrations of glycyrrhizin by Eastern blotting and enzyme-linked immunosorbent assay using anti-glycyrrhizin monoclonal antibody for selective breeding of licorice. J. Nat. Med. 2014, 68, 717-722. [CrossRef] [PubMed]

17. Morinaga, O.; Ishiuchi, K.; Ohkita, T.; Tian, C.; Hirasawa, A.; Mitamura, M.; Maki, Y.; Yasujima, T.; Yuasa, H.; Makino, T. Isolation of a novel glycyrrhizin metabolite as a causal candidate compound for pseudoaldosteronism. Sci. Rep. 2018, 8, 15568. [CrossRef] [PubMed]

18. Ishiuchi, K.; Morinaga, O.; Ohkita, T.; Tian, C.; Hirasawa, A.; Mitamura, M.; Maki, Y.; Kondo, T.; Yasujima, T.; Yuasa, H.; et al. 18ß-glycyrrhetyl-3-O-sulfate would be a causative agent of licorice-induced pseudoaldosteronism. Sci. Rep. 2019, 9, 1587. [CrossRef] [PubMed]

19. Tanaka, H.; Fukuda, N.; Shoyama, Y. Formation of monoclonal antibody against a major ginseng component, ginsenoside Rb1 and its characterization. Cytotechnology 1999, 29, 115-120. [CrossRef] [PubMed] 
20. Sritularak, B.; Morinaga, O.; Yuan, C.S.; Shoyama, Y.; Tanaka, H. Quantitative analysis of ginsenosides Rb1, Rg1, and Re in American ginseng berry and flower samples by ELISA using monoclonal antibodies. J. Nat. Med. 2009, 63, 360-363. [CrossRef] [PubMed]

21. Chao, Z.; Shoyama, Y.; Tanaka, H. Pharmacokinetic study of ginsenosides Rb1 and Rg1 in rat by ELISA using anti-ginsenosides Rb1 and Rg1 monoclonal antibodies. Am. J. Chin. Med. 2006, 34, 1069-1081. [CrossRef] [PubMed]

22. Ma, L.L.; Chao, Z.; Tanaka, H.; Shoyama, Y. Immunodetection of ginsenoside Rb1 in rat serum. Nan Fang Yi Ke Da Xue Xue Bao 2007, 27, 1915-1917. [PubMed]

23. Tanaka, H.; Fukuda, N.; Yahara, S.; Isoda, S.; Yuan, C.S.; Shoyama, Y. Isolation of ginsenoside Rb1 from Kalopanax pictus by eastern blotting using anti-ginsenoside Rb1 monoclonal antibody. Phytother. Res. 2005, 19, 255-258. [CrossRef]

24. Tung, N.H.; Shoyama, Y. Eastern blotting analysis and isolation of two new dammarane-type saponins from American ginseng. Chem. Pharm. Bull. 2012, 60, 1329-1333. [CrossRef]

25. Fukuda, N.; Tanaka, H.; Shoyama, Y. Double staining of ginsenosides by Western blotting using anti-ginsenoside Rb1 and Rg1 monoclonal antibodies. Biol. Pharm. Bull. 2001, 24, 1157-1160. [CrossRef] [PubMed]

26. Tanaka, H.; Fukuda, N.; Shoyama, Y. Eastern blotting and immunoaffinity concentration using monoclonal antibody for ginseng saponins in the field of traditional Chinese medicines. J. Agric. Food Chem. 2007, 55, 3783-3787. [CrossRef] [PubMed]

27. Yokota, S.; Onohara, Y.; Shoyama, Y. Immunofluorescence and immunoelectron microscopic localization of medicinal substance, $\mathrm{Rb1}$, in several plant parts of Panax ginseng. Curr. Drug Discov. Technol. 2011, 8, 51-59. [CrossRef] [PubMed]

28. Fukuda, N.; Tanaka, H.; Shoyama, Y. Formation of monoclonal antibody against a major ginseng component, ginsenoside Rg1 and its characterization. Monoclonal antibody for a ginseng saponin. Cytotechnology 2000, 34, 197-204. [CrossRef] [PubMed]

29. Morinaga, O.; Tanaka, H.; Shoyama, Y. Detection and quantification of ginsenoside Re in ginseng samples by a chromatographic immunostaining method using monoclonal antibody against ginsenoside Re. J. Chromatogr. B Analyt. Technol. Biomed. Life Sci. 2006, 830, 100-104. [CrossRef] [PubMed]

30. Morinaga, O.; Uto, T.; Yuan, C.S.; Tanaka, H.; Shoyama, Y. Evaluation of a new eastern blotting technique for the analysis of ginsenoside Re in American ginseng berry pulp extracts. Fitoterapia 2010, 81, 284-288. [CrossRef] [PubMed]

31. Fukuda, N.; Tanaka, H.; Shoyama, Y. Isolation of the pharmacologically active saponin ginsenoside Rb1 from ginseng by immunoaffinity column chromatography. J. Nat. Prod. 2000, 63, 283-285. [CrossRef] [PubMed]

32. Limsuwanchote, S.; Wungsintaweekul, J.; Yusakul, G.; Han, J.Y.; Sasaki-Tabata, K.; Tanaka, H.; Shoyama, Y.; Morimoto, S. Preparation of a monoclonal antibody against notoginsenoside R1, a distinctive saponin from Panax notoginseng, and its application to indirect competitive ELISA. Planta Med. 2014, 80, 337-342. [CrossRef] [PubMed]

33. Zhu, S.H.; Shimokawa, S.; Tanaka, H.; Shoyama, Y. Development of an assay system for saikosaponin a using anti-saikosaponin a monoclonal antibodies. Biol. Pharm. Bull. 2004, 27, 66-71. [CrossRef] [PubMed]

34. Zhu, S.; Shimokawa, S.; Shoyama, Y.; Tanaka, H. A novel analytical ELISA-based methodology for pharmacologically active saikosaponins. Fitoterapia 2006, 77, 100-108. [CrossRef] [PubMed]

35. Chao, Z.; Cui, Q.; Tian, E.; Zeng, W.; Cai, X.; Li, X.; Tanaka, H.; Shoyama, Y.; Wu, Y. Ultrasensitive time-resolved fluoroimmunoassay for saikosaponin a in Chaihu (Bupleuri Radix). PLoS ONE 2016, 11, e0151032. [CrossRef]

36. Xuan, L.; Tanaka, H.; Xu, Y.; Shoyama, Y. Preparation of monoclonal antibody against crocin and its characterization. Cytotechnology 1999, 29, 65-70. [CrossRef] [PubMed]

37. Tanaka, H.; Goto, Y.; Shoyama, Y. Monoclonal antibody based enzyme immunoassay for Marihuana (cannabinoid) compounds. J. Immunoass. 1996, 17, 321-342. [CrossRef]

38. Morinaga, O.; Uto, T.; Sakamoto, S.; Tanaka, H.; Shoyama, Y. Enzyme-linked immunosorbent assay for total sennosides using anti-sennside A and anti-sennoside B monoclonal antibodies. Fitoterapia 2009, 80, 28-31. [CrossRef]

39. Morinaga, O.; Uto, T.; Sakamoto, S.; Putalun, W.; Lhieochaiphant, S.; Tanaka, H.; Shoyama, Y. Development of eastern blotting technique for sennoside $\mathrm{A}$ and sennoside $\mathrm{B}$ using anti-sennoside $\mathrm{A}$ and anti-sennoside $\mathrm{B}$ monoclonal antibodies. Phytochem. Anal. 2009, 20, 154-158. [CrossRef] [PubMed]

40. Sakamoto, S.; Putalun, W.; Tsuchihashi, R.; Morimoto, S.; Kinjo, J.; Tanaka, H. Development of an enzyme-linked immunosorbent assay (ELISA) using highly-specific monoclonal antibodies against plumbagin. Anal. Chim. Acta 2008, 607, 100-105. [CrossRef] [PubMed]

41. Sakamoto, S.; Taura, F.; Putalun, W.; Pongkitwitoon, B.; Tsuchihashi, R.; Morimoto, S.; Kinjo, J.; Shoyama, Y.; Tanaka, H. Construction and expression of specificity-improved single-chain variable fragments against the bioactive naphthoquinone, plumbagin. Biol. Pharm. Bull. 2009, 32, 434-439. [CrossRef] [PubMed]

42. Sakamoto, S.; Putalun, W.; Pongkitwitoon, B.; Juengwatanatrakul, T.; Shoyama, Y.; Tanaka, H.; Morimoto, S. Modulation of plumbagin production in Plumbago zeylanica using a single-chain variable fragment antibody against plumbagin. Plant Cell Rep. 2012, 31, 103-110. [CrossRef] [PubMed]

43. Kim, J.S.; Tanaka, H.; Shoyama, Y. Immunoquantitative analysis for berberine and its related compounds using monoclonal antibodies in herbal medicines. Analyst 2004, 129, 87-91. [CrossRef] [PubMed]

44. Kim, J.S.; Masaki, T.; Sirikantaramas, S.; Shoyama, Y.; Tanaka, H. Activation of a refolded, berberine-specific, single-chain Fv fragment by addition of free berberine. Biotechnol. Lett. 2006, 28, 999-1006. [CrossRef] [PubMed]

45. Ishiyama, M.; Shoyama, Y.; Murakami, H.; Shinohara, H. Production of monoclonal antibodies and development of an ELISA for solamargine. Cytotechnology 1995, 18, 153-158. [CrossRef] 
46. Putalun, W.; Tanaka, H.; Yahara, S.; Lhieochaiphan, S.; Shoyama, Y. Survey of solasodine-type glycoalkaloids by western blotting and ELISA using anti-solamargine monoclonal antibody. Biol. Pharm. Bull. 2000, 23, 72-75. [CrossRef]

47. Putalun, W.; Tanaka, H.; Shoyama, Y. Rapid separation of solasodine glycosides by an immunoaffinity column using antisolamargine monoclonal antibody. Cytotechnology 1999, 31, 153-158. [CrossRef] [PubMed]

48. Putalun, W.; Taura, F.; Qing, W.; Matsushita, H.; Tanaka, H.; Shoyama, Y. Anti-solasodine glycoside single-chain Fv antibody stimulates biosynthesis of solasodine glycoside in plants. Plant Cell Rep. 2003, 22, 344-349. [CrossRef]

49. Tian, M.; Tanaka, H.; Shang, M.Y.; Karashima, S.; Chao, Z.; Wang, X.; Cai, S.Q.; Shoyama, Y. Production, characterization of a monoclonal antibody against aristolochic acid-II and development of its assay system. Am. J. Chin. Med. 2008, 36, 425-436. [CrossRef] [PubMed]

50. Li, X.W.; Morinaga, O.; Tian, M.; Uto, T.; Yu, J.; Shang, M.Y.; Wang, X.; Cai, S.Q.; Shoyama, Y. Development of an Eastern blotting technique for the visual detection of aristolochic acids in Aristolochia and Asarum species by using a monoclonal antibody against aristolochic acids I and II. Phytochem. Anal. 2013, 24, 645-653. [CrossRef] [PubMed]

51. Li, X.W.; Yokota, S.; Wang, D.; Wang, X.; Shoyama, Y.; Cai, S.Q. Localization of aristolochic acid in mouse kidney tissues by immunohistochemistry using an anti-AA-I and AA-II monoclonal antibody. Am. J. Chin. Med. 2014, 42, 1453-1469. [CrossRef] [PubMed]

52. Wang, D.; Li, X.W.; Wang, X.; Tan, H.R.; Jia, Y.; Yang, L.; Li, X.M.; Shang, M.Y.; Xu, F.; Yang, X.X.; et al. Alpha-actinin-4 is a possible target protein for aristolochic acid I in human kidney cells in vitro. Am. J. Chin. Med. 2016, 44, 291-304. [CrossRef]

53. Pongkitwitoon, B.; Sakamoto, S.; Nagamitsu, R.; Putalun, W.; Tanaka, H.; Morimoto, S. A monoclonal antibody-based enzymelinked immunosorbent assay for determination of homoharringtonine. Planta Med. 2018, 84, 1038-1044. [CrossRef]

54. Sakamoto, S.; Yusakul, G.; Nuntawong, P.; Kitisripanya, T.; Putalun, W.; Miyamoto, T.; Tanaka, H.; Morimoto, S. Development of an indirect competitive immunochromatographic strip test for rapid detection and determination of anticancer drug, harringtonine. J. Chromatogr. B Analyt. Technol. Biomed. Life Sci. 2017, 1048, 150-154. [CrossRef]

55. Sakamoto, S.; Miyamoto, T.; Usui, K.; Tanaka, H.; Morimoto, S. Sodium-periodate-mediated harringtonine derivatives and their antiproliferative activity against HL-60 acute leukemia cells. J. Nat. Prod. 2018, 81, 34-40. [CrossRef]

56. Fujii, S.; Morinaga, O.; Uto, T.; Nomura, S.; Shoyama, Y. Development of a monoclonal antibody-based immunochemical assay for liquiritin and its application to the quality control of licorice products. J. Agric. Food Chem. 2014, 62, 3377-3383. [CrossRef] [PubMed]

57. Kido, K.; Morinaga, O.; Shoyama, Y.; Tanaka, H. Quick analysis of baicalin in Scutellariae radix by enzyme-linked immunosorbent assay using a monoclonal antibody. Talanta 2008, 77, 346-350. [CrossRef] [PubMed]

58. Yusakul, G.; Togita, R.; Minami, K.; Chanpokapaiboon, K.; Juengwatanatrakul, T.; Putalun, W.; Tanaka, H.; Sakamoto, S.; Morimoto, S. An indirect competitive enzyme-linked immunosorbent assay toward the standardization of Pueraria candollei based on its unique isoflavonoid, kwakhurin. Fitoterapia 2019, 133, 23-28. [CrossRef]

59. Chanpokapaiboon, K.; Khoonrit, P.; Yusakul, G.; Juengwatanatrakul, T.; Putalun, W.; Tanaka, H.; Sakamoto, S.; Morimoto, S. A recombinant Fab antibody against kwakhurin as a tool for sensitive indirect competitive ELISA. Curr. Pharm. Biotechnol. 2018, 19, 1170-1176. [CrossRef]

60. Qu, H.; Zhang, G.; Li, Y.; Sun, H.; Sun, Y.; Zhao, Y.; Wang, Q. Development of an enzyme-linked immunosorbent assay based on anti-puerarin monoclonal antibody and its applications. J. Chromatogr. B Analyt. Technol. Biomed. Life Sci. 2014, 120-125. [CrossRef]

61. Qu, H.; Qu, B.; Wang, X.; Zhang, Y.; Cheng, J.; Zeng, W.; Liu, S.; Wang, Q.; Zhao, Y. Rapid, sensitive separation of the three main isoflavones in soybean using immunoaffinity chromatography. J. Sep. Sci. 2016, 39, 1195-1201. [CrossRef]

62. Qu, H.; Zhang, Y.; Qu, B.; Cheng, J.; Liu, S.; Feng, S.; Wang, Q.; Zhao, Y. Novel immunoassay and rapid immunoaffinity chromatography method for the detection and selective extraction of naringin in Citrus aurantium. J. Sep. Sci. 2016, 39, 1389-1398. [CrossRef]

63. Ma, W.; Wang, C.; Liu, R.; Wang, N.; Lv, Y.; Dai, B.; He, L. Advances in cell membrane chromatography. J. Chromatogr. A 2021, 1639, 461916. [CrossRef]

64. Ratan, Z.A.; Haidere, M.F.; Hong, Y.H.; Park, S.H.; Lee, J.O.; Lee, J.; Cho, J.Y. Pharmacological potential of ginseng and its major component ginsenosides. J. Ginseng Res. 2021, 45, 199-210. [CrossRef]

65. Christensen, L.P. Ginsenosides chemistry, biosynthesis, analysis, and potential health effects. Adv. Food Nutr. Res. 2009, 55, 1-99.

66. United States Pharmacopeial Convention. United States Pharmacopeia 43-National Formulary 38; United States Pharmacopeial Convention: North Bethesda, ML, USA, 2020.

67. Pharmaceutical and Medical Device Regulatory Science Society of Japan. Japanese Pharmacopoeia, 17th ed.; (JP XVII); Jiho: Tokyo, Japan, 2016.

68. Goda, Y.; Hakamazuka, T. Kampo Medicines Manufacturers' Association under the super vision of National Institute of Health Sciences, the affiliated institutions of the Ministry of Health, Labour and Welfare of Japan. In Handbook on OTC Medicinal Products in Kampo; Jiho: Tokyo, Japan, 2013.

69. Asl, M.N.; Hosseinzadeh, H. Review of pharmacological effects of Glycyrrhiza sp. and its bioactive compounds. Phytother. Res. 2008, 22, 709-724. [CrossRef] [PubMed]

70. Bell, R.F.; Moreira, V.M.; Kalso, E.A.; Yli-Kauhaluoma, J. Liquorice for pain? Ther. Adv. Psychopharmacol. 2021, 11, 20451253211024873. [CrossRef] [PubMed] 
71. Petramfar, P.; Hajari, F.; Yousefi, G.; Azadi, S.; Hamedi, A. Efficacy of oral administration of licorice as an adjunct therapy on improving the symptoms of patients with Parkinson's disease, a randomized double blinded clinical trial. J. Ethnopharmacol. 2020, 247, 112226. [CrossRef]

72. Wang, Z.Y.; Nixon, D.W. Licorice and cancer. Nutr. Cancer 2001, 39, 1-11. [CrossRef]

73. Han, Y.X.; Jia, Q.J.; Yang, D.F.; Chai, W.G.; Zhang, X.M.; He, Q.L.; Liang, Z.S. Current advances in environmental stimuli regulating the glycyrrhizic acid biosynthesis pathway. Fitoterapia 2021, 151, 104860. [CrossRef]

74. Zhang, Q.; Ye, M. Chemical analysis of the Chinese herbal medicine Gan-Cao (licorice). J. Chromatogr. A 2009, 1216, 1954-1969. [CrossRef]

75. Baker, Z.K.; Sardari, S. Molecularly imprinted polymer (MIP) applications in natural product studies based on medicinal plant and secondary metabolite analysis. Iran Biomed. J. 2021, 25, 68-77. [CrossRef] [PubMed]

76. Mora-Granados, M.; González-Gómez, D.; Jeong, J.; Gallego-Picó, A. A molecularly imprinted polymer for delective extraction of phenolic acids from human urine. Appl. Sci. 2021, 11, 1577. [CrossRef]

77. Uto, T.; Morinaga, O.; Tanaka, H.; Shoyama, Y. Analysis of the synergistic effect of glycyrrhizin and other constituents in licorice extract on lipopolysaccharide-induced nitric oxide production using knock-out extract. Biochem. Biophys. Res. Commun. 2012, 417, 473-478. [CrossRef]

78. Uto, T.; Tung, N.H.; Morinaga, O.; Shoyama, Y. Interaction analysis of glycyrrhizin on licorice extract-induced apoptosis of human leukemia cells by knockout extract. Nat. Prod. Chem. Res. 2013, 1, 105. [CrossRef]

79. Hsu, Y.C.; Chang, P.J.; Tung, C.W.; Shih, Y.H.; Ni, W.C.; Li, Y.C.; Uto, T.; Shoyama, Y.; Ho, C.; Lin, C.L. De-glycyrrhizinated licorice extract attenuates high glucose-stimulated renal tubular epithelial-mesenchymal transition via suppressing the Notch2 signaling pathway. Cells 2020, 9, 125. [CrossRef] [PubMed] 